Short reports

\title{
Rapidly progressive glomerulonephritis complicating acute rheumatic fever
}

\author{
Marwan S Akasheh, Mohammed Al-Lozi, Hani B Affarah, Fayez K Hajjiri, Salah \\ Al-Jitawi
}

\begin{abstract}
Summary
A case of acute rheumatic fever and glomerulonephritis following streptococcal throat infection is presented. The coincidence of rheumatic fever and poststreptococcal glomerulonephritis is uncommon, but well recognised. This case is of additional interest since the nephritis was crescentic.
\end{abstract}

Keywords: rheumatic fever, glomerulonephritis, streptococcal antigens

Acute rheumatic fever and acute post-streptococcal glomerulonephritis share a common pathogenetic basis, both being a consequence of streptococcal superantigens. ${ }^{1}$ A strong body of evidence supports the concept of coexistence of nephritogenic and rheumatogenic strains. ${ }^{2}$ Renal involvement in acute rheumatic fever is usually mild and transient. We report the simultaneous occurrence of diffuse proliferative glomerulonephritis with crescents and acute rheumatic fever.

\section{Case report}

A 32-year-old Jordanian male, presented with fever, rigors, puffiness of the eyes, tea-coloured urine, increasing dyspnoea, and right flank pain of a few days duration. Two weeks earlier, he had a sore throat with constitutional symptoms for which he had received amoxicillin. The patient was previously healthy, did not smoke or abuse drugs, and was heterosexual. On examination, he was febrile $\left(39^{\circ} \mathrm{C}\right)$ with a blood pressure of $160 / 110 \mathrm{mmHg}$. He had peri-orbital and mild lower limb oedema. Fundoscopy was normal. The throat was mildly congested. The jugular venous pressure was raised with bilateral basal crepitations. The apical beat was displaced to the left. The second heart sound was loud. There was a blowing decrescendo diastolic murmur along the left sternal border. The rest of the examination was normal. Laboratory data revealed normocytic normochromic anaemia, and an erythrocyte sedimentation rate of $95 \mathrm{~mm}$ in first hour. Urinalysis showed a brown discolouration, with a specific gravity 1.012 , protein +3 , 25-30 white blood cells per high power field, abundant red blood cells, with several coarse granular and red blood cell casts. Blood urea nitrogen was $54.7 \mathrm{mmol} / \mathrm{l}$, and serum creatinine level $308 \mu \mathrm{mol} / \mathrm{l}$; serum sodium, potassium, and chloride were normal; serum bicarbonate $20 \mathrm{mmol} / \mathrm{l}$; serum calcium $1.7 \mathrm{mmol} / 1$, serum phosphorus $3.52 \mathrm{mmol} / \mathrm{l}$; liver enzymes were normal; antistreptolysin $O$ titer 1:800 ToddU; C-reactive protein +2 ; antinuclear antibodies, rheumatoid factor, hepatitis B SAg, Coomb's test and VDRL were negative; $\mathrm{C} 3$ was $0.36 \mathrm{~g} / 1$ (normal, 0.7-1.6 g/1), C4 was $0.32 \mathrm{~g} / \mathrm{l}$ (normal, $0.2-0.4 \mathrm{~g} / \mathrm{l}$ ), normal serum protein electrophoresis. A 24-h urine collection showed a creatinine clearance of $43 \mathrm{ml} / \mathrm{min}$, with $2 \mathrm{~g}$ of protein. Blood, urine, and throat swab cultures were negative. Cardiomegaly with pulmonary congestion were present on chest X-ray. Electrocardiogram showed evidence of left ventricular strain. Echocardiogram showed an enlarged left ventricular end diastolic diameter, aortic regurgitation with no vegetations. On abdominal ultrasonography the kidneys were enlarged with increased echogenicity.

The patient was started on benzylpenicillin $16 \mathrm{MU}$ daily, cefotaxime $1 \mathrm{~g}$ intravenously twice daily, furosemide $80 \mathrm{mg}$, digoxin 0.125 $\mathrm{mg}$, and hydralazin $100 \mathrm{mg}$ po daily. He continued to have fever, dyspnoea, with decreased urine output to less than $500 \mathrm{ml}$ daily. There was no change in his medical condition over the ensuing days, although his antibiotics were changed to cover suspected infective endocarditis. On the tenth hospital day, his serum creatinine was $783 \mu \mathrm{mol} / 1$. A percutaneous kidney biopsy showed diffuse proliferative and exudative glomerulonephritis with crescent formation. The glomeruli were moderately hypercellular with increased mesangial and endothelial cells and leucocytic infiltrate. Onethird of the glomeruli showed parietal cell proliferation with crescent formation (figure). There was mild interstitial oedema and focal leukocytic infiltration. Some of the proximal tubules were dilated and contained red blood cells. The blood vessels were unremarkable.

A few days later he developed left ankle arthritis which also appeared in the right wrist. Salicylates and prednisolone were administered. The fever and arthritis subsided and urine output increased to around one litre daily. Six months later, his serum creatinine was $115 \mu \mathrm{mol} / 1$.

\section{Discussion}

Streptococcal upper respiratory tract infections remain common, but with acceptable 


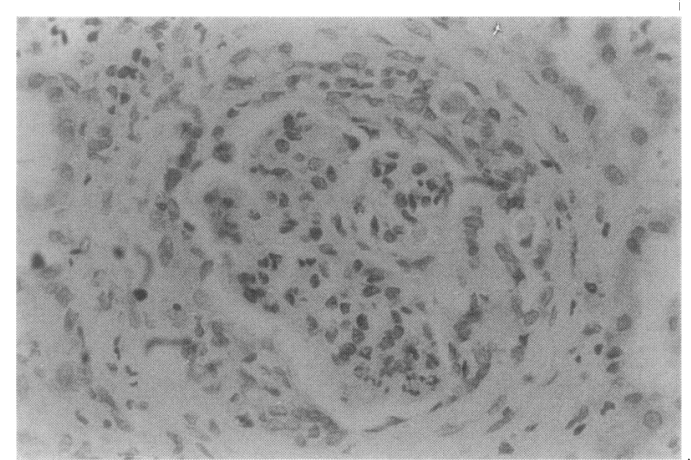

Figure A high-power view showing crescent formation and leucocytic infiltrate of the glomerulus $(\mathrm{H} \& \mathrm{E}$ stain $\times 400$ )

morbidity. However, recent medical literature has shown a resurgence of acute rheumatic fever. ${ }^{3-6}$ Acute rheumatic fever is an inflammatory disease with multisystem involvement (arthritis, carditis, chorea). The prevalence of renal abnormalities is still unknown, as it has only received scant attention. The first observation of renal involvement in acute rheumatic fever was in 1840 when Rayer coined the term 'rheumatic nephritis'. ${ }^{7}$ Mild haematuria and proteinuria occur transiently in an appreciable number of patients (up to $51 \%$ ). In pathologic studies, the frequency of renal involvement has varied from less than $1 \%$ to as high as $39 \%$. A wide range of clinical and pathological renal abnormalities have been described as shown in box 1 . In 1967, Grishman et al were the first to report on the results of renal biopsies in a prospective study relating the two diseases. Out of 22 patients with acute rheumatic fever three had a mild diffuse glomerulonephritis; two a focal glomerulonephritis; and one severe glomerulonephritis. In 1981, Gibney et $a l^{\beta}$ reported the first case of simultaneous occurrence of classic acute exudative poststreptococcal glomerulonephritis and acute rheumatic fever, while in 1983 Escudero et al ${ }^{\top}$ reported a similar finding in a patient with fulminant acute rheumatic fever and multisystem involvement. We report here the coexistence of diffuse proliferative glomerulonephritis with crescents and acute rheumatic fever. The causes of rapidly progressive glomerulonephritis are listed in box 2 . The patient had two complications of streptococcal infection, namely, rapidly progressive glomerulonephritis and rheumatic fever. There was an isolated aortic regurgitation, and a late developing arthritis. This may suggest a different trend of the disease than previously noted. Rheumatic fever was described in the early 80 s as a 'vanishing

1 Schlievert PM. Role of superantigens in human disease. $\mathcal{F}$ Infect Dis 1993; 167: 997-1002.

2 Bisno AL, Pearce IA, Wall HP, Moody MD, Stollerman GH. Contrasting epidemiology of acute rheumatic fever and acute glomerulonephritis: nature of the antecedent strepacute glomerulonephritis: nature of the antecedent

3 Veasy LG, Wiedmeier SE, Orsmond GS, et al. Resurgence of acute rheumatic fever in the intermountain area of the of acute rheumatic fever in the intermountain area
United States. $N$ Engl $₹$ Med 1987; 316: 421-7.

4 United States. N Engl f Med 1987; 316: 421-7. Hosier DM, Craenen JM, Teske DW, Wheller JJ.
Resurgence of acute rheumatic fever. Am $\mathcal{F}$ Dis Child 1987; 141: 730-3.

5 Congeni B, Rizzo C, Congeni J, Streenvasan VV. Outbreak of acute rheumatic fever in northeast Ohio. $\mathcal{F}$ Pediatr 1987; 111: $176-9$
Renal features of acute rheumatic fever:

Clinical:

- haematuria

- proteinuria

- mild elevation of renal functions

- non-progressive

Pathological:

- focal glomerulitis

- mild diffuse proliferation

- interstitial nephritis

Box 1

\section{Causes of rapidly progressive glomerulonephritis:}

- Primary glomerular diseases:

Type I: anti-glomerular basement membrane (no pulmonary haemorrhage)

Type II: immune complex

Type III: pauci immune superimposed on: IgA nephropathy, membranoproliferative GN (II), membranous

- Multisystem diseases: systemic lupus erythematosus, Henoch-Schönlein purpura, vasculitis, cryoglobulinaemia, Goodpasture (anti-glomerular basement membrane with pulmonary haemorrhage), malignancies

- Postinfectious: streptococcal, staphylococcal, infective endocarditis, visceral sepsis, hepatitis B, Legionnaire's disease

- Medications

allopurinol, rifampicin

Box 2

\section{Learning points}

- wary physicians must not misinterpret acute rheumatic fever for infective endocarditis Jones criteria remain the cornerstone in diagnosis

- there is evidence of resurgence of acute rheumatic fever; adults are not immune as demonstrated by this case

- transient haematuria and proteinuria occur in an appreciable number of patients with acute rheumatic fever

- crescentic nephritis may occur with acute rheumatic fever

- steroids are not helpful in post-streptococcal glomerulonephritis, but when associated with acute rheumatic fever the response is dramatic

\section{Box 3}

disease in suburbia'; ${ }^{10}$ doctors, especially in developing countries, must not forget this vanishing disease.

6 Burns DL, Ginsberg CM. Recrudescence of acute rheumatic fever in Dallas, Texas. In: Proceedings of the Society for Pediatric Research. Pediatr Res 1987; abstr 496. Grishman E, Cohen S, Salomon MD, Churg J. Renal lesion in acute rheumatic fever. Am F Pathol 1967; 51: 1045-61 Gibney R, Reineck HJ, Bannayan GA, Stein JH. Renal lesions in acute rheumatic fever. Ann Intern Med 1981; 94:

Escudero J, Stanislawsky E, Escudero X. Fulminant acute rheumatic fever with multisystem involvement. Am Heart $\mathcal{f}$ 1983; 105: $161-6$

10 Land MA, Bisno AL. Acute rheumatic fever: a vanishing disease in suburbia. $\mathfrak{F A M A} 1983 ; 2449: 895-8$. 